\title{
Vesicular lesions in a neonate: what's your diagnosis?
}

Lesões vesiculares em recém-nascido: qual é seu diagnóstico?

\author{
Marta Sofia da Cunha Alves Machadoํㅡㄹ Elsa Cristina de Freitas Lima Teixeira ${ }^{2}$, \\ Lígia Maria Nogueira Ferreira², Lígia Raquel Gonçalves Basto ${ }^{3}$
}

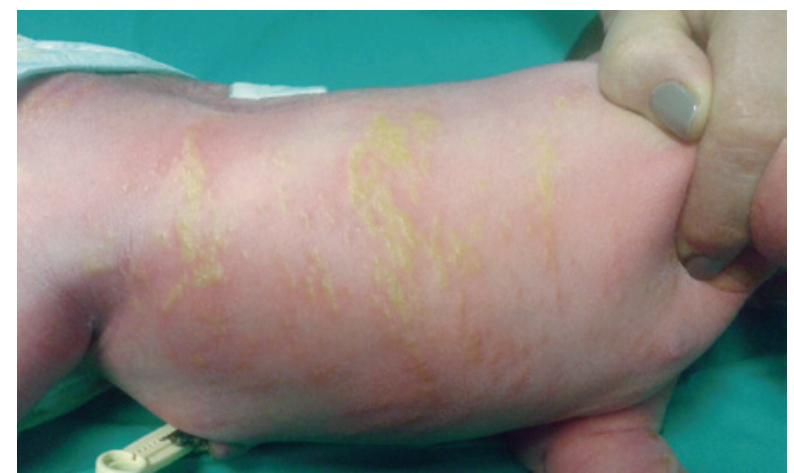

Figure 1. Hyperpigmented linear skin lesions following Blaschko lines

Incontinentia pigmenti (IP) is a rare genodermatosis transmitted as an X-linked dominant trait, occurring in 1:50,000 newborns. ${ }^{(1-3)}$ It is frequently lethal in males. ${ }^{(1-3)}$ In this disease, basal cells in the epidermis lose melanin that is collected in the dermis. ${ }^{(2,3)}$ Typically, skin manifestations progress through four stages: vesicular (evident at birth or within the first few postnatal weeks); verrucous; hyperpigmented, and hypopigmented. ${ }^{(1-3)}$ Extracutaneous involvement occurs in $80 \%$ of patients. ${ }^{(1)}$ A skin biopsy and/or genetic testing for mutations in NEMO/IKK-gamma confirm the disease..$^{(1-4)}$

A female full-term newborn presented with multiple vesicular lesions in the first 12 hours of life. Given the suspicion of neonatal herpes, she was initiated on acyclovir. Detection of herpes simplex virus by culture and polymerase chain reaction were negative (blood and skin lesions). Within 36 hours, vesicular and hyperpigmented linear skin lesions were apparent, distributed along Blaschko lines, evoking IP. At this time,

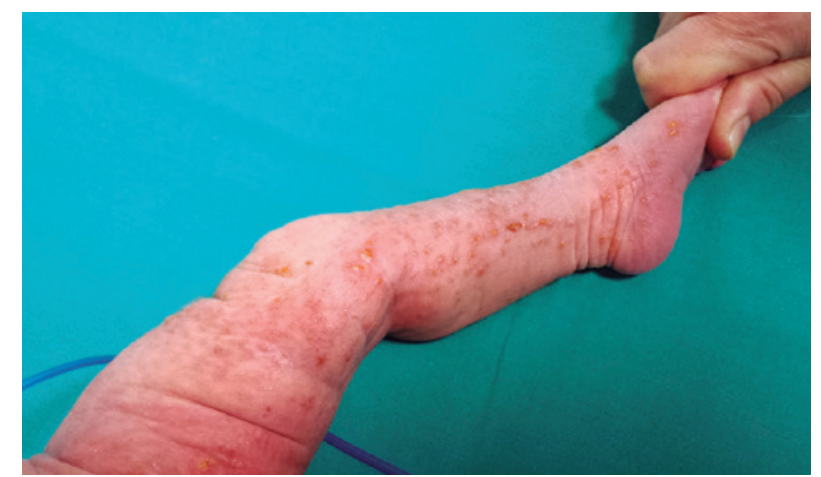

Figure 2. Hyperpigmented linear skin lesions on the leg

the mother revealed that she and her older daughter also had some kind of "water bubbles" at birth, information that supported the diagnosis.

In IP, a high level of suspicion is necessary. Differential diagnosis of IP varies according to the stage of the disease. ${ }^{(1-5)}$ In the first stage, it can be confused with herpes simplex, epidermolysis bullosa, or bullous pemphigoid..$^{(1,5)}$ Since neonatal herpes and IP can coexist, early treatment with acyclovir should be started until definitive diagnosis is made..$^{(1,3)}$ The differential diagnosis of verrucous stage is limited and includes linear epidermal nevus. ${ }^{(1)}$ The hyperpigmented stage is IP's hallmark, but may be mistaken for linear and whorled nevoid hypomelanosis. ${ }^{(1,5)}$ The hypopigmented stage can be misdiagnosed as hypomelanosis of Ito or vitiligo. ${ }^{(1,5)}$

The prognosis of IP is generally good, but a periodic assessment by a multidisciplinary team should be made to rule out visual, motor, or intellectual impairment. ${ }^{(1-3)}$ Genetic counseling is of the utmost importance. ${ }^{(2,3)}$

\footnotetext{
Centro Hospitalar do Baixo Vouga, Aveiro, Portugal.

${ }^{2}$ Centro Hospitalar Tondela-Viseu, Viseu, Portugal.

${ }^{3}$ Maternidade Dr. Daniel de Matos, Coimbra, Portugal.

Corresponding author: Marta Sofia da Cunha Alves Machado - Avenida Artur Ravara, s/n - Zip code: 3814-501 - Aveiro, Portugal - Phone: +351915540885 - E-mail: marta.scamachado@gmail.com Received on: Feb 18, 2016 - Accepted on: July 4, 2016

DOI: 10.1590/S1679-45082016Al3655
} 


\section{ACKNOWLEDGMENT}

José Carlos Cardoso, Dermatology Department of Centro Hospitalar e Universitário de Coimbra (Portugal).

\section{REFERENCES}

1. Ehrenreich M, Tarlow MM, Godlewska-Janusz E, Schwartz RA. Incontinentia pigmenti (Bloch-Sulzberger syndrome): a systemic disorder. Cutis. 2007;79(5): 355-62. Review.

2. Shah L, Balakumar G. Visual diagnosis: a persistent newborn rash. Pediatr Rev. 2007;28(11):429-32.
3. Rodrigues V, Diamantino F, Voutsen O, Cunha MS, Barroso R, Lopes MJ, et al. Incontinentia pigmenti in the neonatal period. BMJ Case Rep. 2011;2011. pii: bcr0120113708.

4. Scheuerle AE, Ursini MV. Incontinentia Pigmenti. 1999 Jun 8 [updated 2015 Feb 12]. In: Pagon RA, Adam MP, Ardinger HH, Wallace SE, Amemiya A, Bean LJ, Bird TD, Fong CT, Mefford HC, Smith RJ, Stephens K, editors. GeneReviews ${ }^{\circledR}$ [Internet]. Seattle (WA): University of Washington, Seattle; 1993-2016. Available from: http://www.ncbi.nlm.nih.gov/books/NBK1472/

5. Vashi N, Kundu R. Approach to the patient with hyperpigmentation disorders [Internet]. Uptodate; 2016 [cited 2016 Jul 1]. Available from: http://www. uptodate.com 